\title{
WEBSITE DESIGN SEBAGAI EKSPANSI PASAR UNTUK PENGRAJIN TENUN SOPPENG
}

\author{
Mutia Tri Satya \\ rafi_afia@yahoo.com \\ Yuyus Yudistria \\ y.yudistria@yahoo.com
}

\section{SEKOLAH TINGGI ILMU EKONOMI EKUITAS}

\begin{abstract}
ABSTRAK
Tujuan kegiatan pengabdian ini adalah untuk meningkatkan promosi dan informasi yang didapat oleh masyarakat tentang tenun sutera Soppeng serta penggunaan media promosi tidak hanya mengandalkan media sosial dimana sangat terbatas jangkauannya. Metode dalam pelaksanaan dilakukan beberapa tahap seperti; 1). Berdiskusi dengan pengrajin tenun Soppeng mengenai keuntungan menggunakan website. 2). Memberikan website design dari berbagai referensi yang diambil. Dalam hal ini kami mengambil referensi dari website tenun yang telah ada sebagai perbandingan. Pelatihan penggunaan website Monitoring dan Evaluasi. Dengan melakukan program kegiatan pengabdian yang diharapkan dapat mempromosikan tenun ini sehingga bisa lebih dikenal oleh masyarakat luas dan semakin meningkatkan penjualan dimana dengan kegiatan-kegiatan yang kami lakukan pemasaran tenun cantika mengalami sekitar $10 \%$ peningkatan penjualan dan semakin banyak konsumen yang mengenal tenun cantika. Dengan program-program yang ditelah susun dapat memperluas pasar tenun cantika dan memperomosikan tenun ini tidak hanya di Sulawesi Selatan tetapi ke Seluruh Indonesia.
\end{abstract}

Kata kunci: Promosi Dan Informasi; Website Design.

\section{PENDAHULUAN}

Kabupaten Soppeng adalah salah satu Kabupaten di provinsi Sulawesi Selatan, Indonesia. Ibu kota kabupaten ini terletak di Watansoppeng. Kabupaten ini memiliki luas wilayah $1.359,44 \mathrm{~km}^{2}$ dan berpenduduk sebanyak kurang lebih 223.826 jiwa.

Soppeng terletak pada depresiasi Sungai Walanae yang terdiri dari daratan dan perbukitan dengan luas daratan \pm 700 $\mathrm{km}^{2}$ serta berada pada ketinggian rata-rata antara 100-200 m di atas permukaan laut. Luas daerah perbukitan Soppeng kurang lebih $800 \mathrm{~km}^{2}$ dan berada pada ketinggian rata-rata $200 \mathrm{~m}$ di atas permukaan laut. Ibu kota Kabupaten Soppeng adalah kota Watansoppeng yang berada pada ketinggian $120 \mathrm{~m}$ di atas permukaan laut.

Kabupaten Soppeng memiliki tempat-tempat wisata berupa permandian air panas alami yang bernama "LEJJA", permandian mata air "OMPO" dan permandian alam "CITTA". Lejja berjarak \pm 40 Kilometer dari pusat kota, terletak di desa Batu-batu, Kecamatan Marioriawa. 
Soppeng sedang giat untuk mengembangkan pariwisata. Berbagai promosi dengan gencar dilakukan. Meningkatnya jumlah pariwisata otomatis akan berdampak salah satunya terhadap perekonomian. Untuk itulah Soppeng berusaha memberdayakan UKM dan terus menciptakan Wirausaha baru. Salah satunya yang menjadi perhatian saat ini adalah tenun sutera. Tenun ini berusaha terus dipertahankan mengingat jumlah pengusaha tenun yang semakin sedikit. Kalau berkurang terus, maka hilanglah tenun sutera khas Soppeng.

Tahun 1960an Soppeng merupakan sebuah pusat pemintalan sutera yang besar dan terbaik di Indonesia. Begitu populernya sutera Soppeng sampai Presiden Soeharto saat itu datang ke lokasi pembuatan sutera. Beberapa kali presiden Indonesia kedua ini mengunjungi daerah ini, hingga lapangan tempat mendarat helikopternya pun diberi nama Lapangan Soeharto.

Petani sutera Soppeng hanya menghasilkan benang sutera saja. Benang yang dipintal dijual ke Sengkang, sehingga Sengkang lebih dikenal penghasil sutera dibanding Soppeng. Seiring berjalannya waktu Soppeng mencoba membuat tenun dengan ciri khas yang sama,yaitu motif lagosi yang artinya bunga-bunga. Lagosi itu adalah nama kampung didaerah dengan Sengkang. Dulu hanya orang Lagosi yang bisa membuat tenun seperti ini. Tapi seiring perkembangan jaman semua pengrajin tenun bisa membuat motif lagosi ini. Inilah mulainya bermunculan pengusaha tenun walaupun jumlahnya tidak banyak.

Tahun 1990an petani sutera mencapai 1000 orang lebih. Bahkan setiap rumah di Soppeng selalu ada murbei. Tapi karena tidak ada kejelasan dari pemerintah mengenai bentuk regulasi pasar sutera, maka pada tahun 2000 petani sutera menurun sampai $80 \%$. Dahulu memang ada Perum Pesuteraan yang menjadi pusat penelitian sutera di Soppeng, tapi sekitar tahun 2000 Perum Pesuteraan ini memudar. Tidak ada lagi pusat penelitian ulat sutera, sehingga tidak ada lagi yang memperhatikan lagi masalah ulat sutera. Terutama dalam hal perkembangbiakkan. Bibit sutera pernah diberikan secara gratis oleh perum, bibit dengan kualitas bagus. Tapi malah semakin membuat ulat sutera mati. Melihat sutera tidak begitu menjanjikan maka petani lebih memilih menanam yang lain, seperti cokelat dan jagung.

Masalah baru di daerah Soppeng, petani yang beralih ke cokelat dan petani yang tetap bertahan dengan ulat suteranya. Ulat sutera itu sangat sensitif, mencium bau, ulat itu akan mati. Petani yang menanam coklat, membuat ulat sutera yang disebelahnya mati.

Petani ulat sutera ini tidak terlalu berkembang, tetapi terdapat usaha tenun yang dimulai tahun 1999 dan masih bertahan hingga kini. Usaha tenun ini potensi untuk dikembangkan. Bahkan pasarnya pernah sampai ke Jawa. Awalnya hanya penjahitan saja, kemudian dikembangkan hingga usaha bordir. Kelompok usaha yang dibentuk bernama Cantika. Untuk penegasan di Bugis itu pakai Ka. Cantik.ka. Cantik hati, cantik kata, cantik rupa. Kelompok usaha ini terbentuk tahun 2010. Hingga saat ini, jumlah anggotanya mencapai 30, yang terbagi menjadi kelompok usaha tenun dan jahit. Dan usaha khusus tenun ada 3 orang. Masing-masing diberi alat tenunnya untuk dikerjakan di rumah. Untuk harga alat tenun bukan mesin sekitar R. 5.000.000,00. Sisa anggota Cantika, diberikan bahan, didesain dan diberikan warna. Mereka tinggal menjahit sesuai yang diinginkan. Biaya jahit per potong tergantung model yang dibuat dengan kisaran antara Rp 80.000,00 sampai Rp 200.000,00 dan untuk tenun Rp $10.000,00$ per meter.

Harga tenun Walida 50\% sabbe, apabila benangnya dari ulat sutera harganya bisa mencapai Rp 500.000,00. Terdapat variasi warna merah, hitam, putih, pink, kuning, hijau. Ada juga yang benang campuran, dengan harga $\mathrm{Rp} 300.000,00$. Terdapat pula tenun walida dengan berbagai warna coklat, biru, marun, emas. Paling 
mahal tenun walida juga, $100 \%$ sutera dengan harga mencapai Rp1.300.000,00 dengan warna hitam, kuning, biru. Namun, tenun Cantikka dalam promosi dan informasi masih kurang, serta penggunaan media promosi tenun Cantikka belum mengandalkan media sosial. Sehingga berdasarkan kondisi tersebut tenun Cantikka perlu dibantu dalam pembuatan media promosi dan informasi baik melalui brosur, media sosial maupun website.

\section{METODOLOGI PELAKSANAAN}

Tabel Metode Pelaksanaan Pengabdian

\begin{tabular}{|c|c|c|}
\hline TAHAPAN & METODE & HASIL \\
\hline Tahap awal & $\begin{array}{l}\text { - Wawancara } \\
\text { Berdiskusi dengan pengrajin tenun Soppeng } \\
\text { mengenai keuntungan menggunakan } \\
\text { website. } \\
\text { - Identifikasi Kebutuhan } \\
\text { Memberikan website design dari berbagai } \\
\text { referensi yang diambil. Dalam hal ini kami } \\
\text { mengambil referensi dari website tenun yang } \\
\text { telah ada sebagai perbandingan, } \\
\text { diantaranya: } \\
\text { http://www.tokokaintextileonline.com } \\
\underline{\text { http://bahankain.com }} \\
\underline{\text { http://gloriatextitile.co.id }}\end{array}$ & $\begin{array}{l}\text { - Pemahaman yang } \\
\text { mendalam tentang } \\
\text { pentingnya } \\
\text { menggunakan } \\
\text { website }\end{array}$ \\
\hline Tahap pelaksanaan & - Pelatihan penggunaan website & 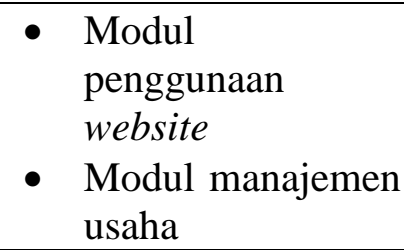 \\
\hline Tahap akhir & - Monitoring dan Evaluasi & $\begin{array}{l}\text { Pendampingan sampai } \\
\text { tercipta kemandirian } \\
\text { pelaku usaha }\end{array}$ \\
\hline
\end{tabular}

\section{HASIL dan LUARAN}

Mengatasi permasalahan yang dihadapi oleh kelompok usaha Tenun Cantikka dalam hal kurangnya promosi dan minimnya informasi yang didapat oleh masyarakat tentang tenun sutera Soppeng selain itu juga media promosi yang tidak mengandalkan media sosial, sehingga sangat terbatas jangkauannya. Sehingga tim melakukan kegiatan yang diharapkan dapat membantu mempromosikan tenun ini sehingga bisa lebih dikenal oleh masyarakat luas dan semakin meningkatkan penjualan. Adapun berdasarkan pelakanaan tim maka dihasilkan sebagai berikut:
1. Pembuatan website www.cantikasabbena.com

Tujuan dalam pembuatan website www.cantikasabbena.com adalah untuk memperluas informasi dan promosi terkait dengan hasil produk tenun cantikka adapun targetnya adalah selain untuk wilayah Sulawesi Selatan tetapi ke seluruh Indonesia bahkan diharapkan dapat melakukan ekspor.

2. Pembuatan Brosur

Pembuatan brosur yang dilakukan adalah selain dapat digunakan dalam keikutsertaan dalam kegiatan pameran juga dapat disebar di 
beberapa hotel yang terdapat di Makasar atau Kabupaten wilayah Sulawesi Selatan .

3. Pembuatan Kartu Nama

Sejauh ini pelaku usaha belum memiliki kartu nama sehingga di buatkannya konsep model kartu nama serta percetakan kartu nama yang dapat digunakan dalam keikutsertaan dalam kegiatankegiatan yang dilakasanakan oleh pemda (pameran, seminar) sehingga sebagai salah satu sarana informasi.
4. Merancang Desain foto tenun agar terlihat lebih menarik ketika dipajang di website

Dirancangnya desain foto untuk tampilan website adalah bertujuan untuk membuat menarik website sehingga menjadi konsumen tertarik dalam mengakses website, serta memperluas informasi dan promosi produk-produk tenun yang dihasilkan Cantikka.

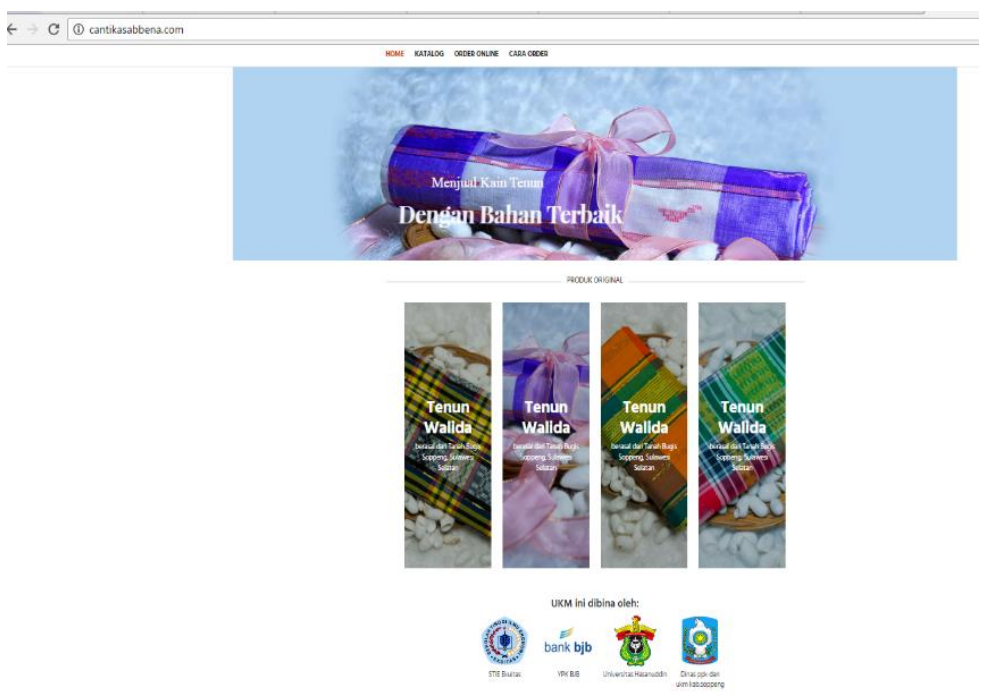

Gambar 1. Website Tenun Cantikka

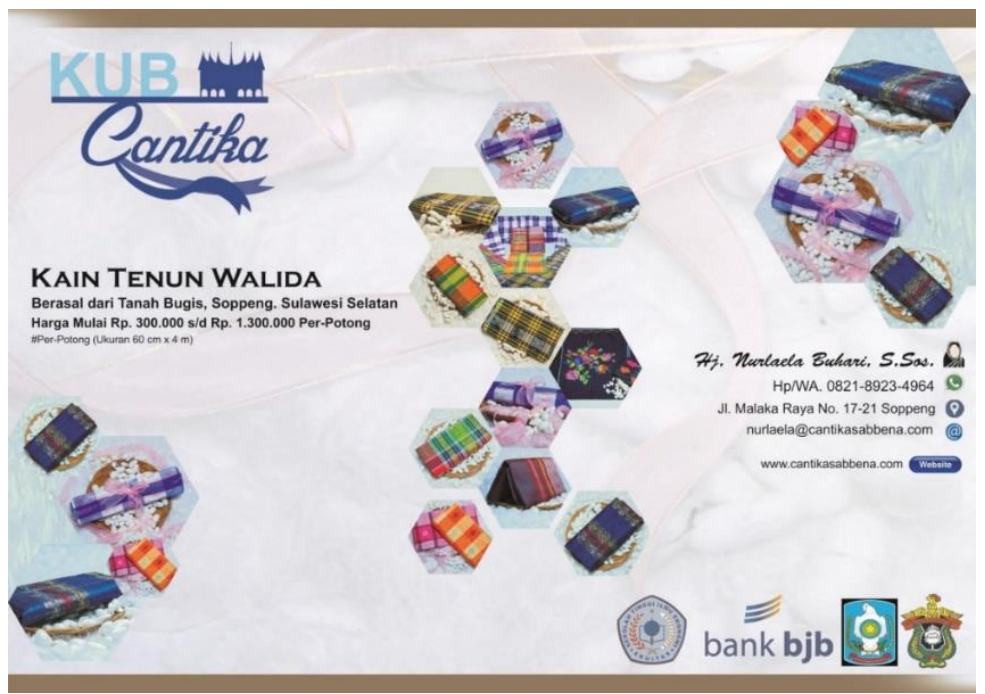

Gambar 2. Brosur 


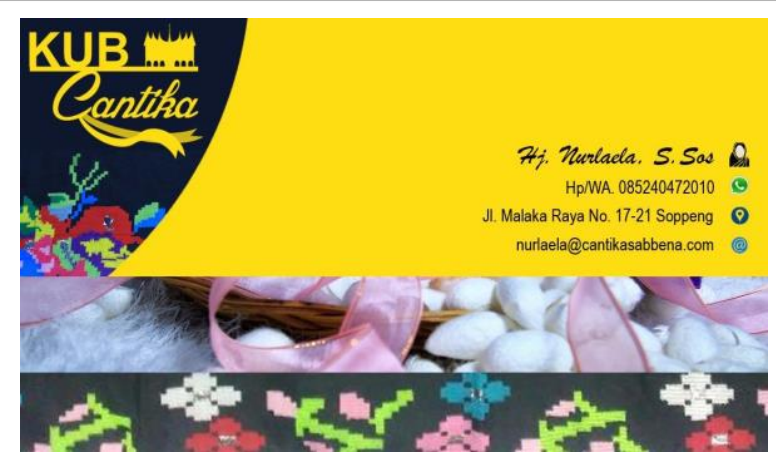

Gambar 3 Kartu Nama

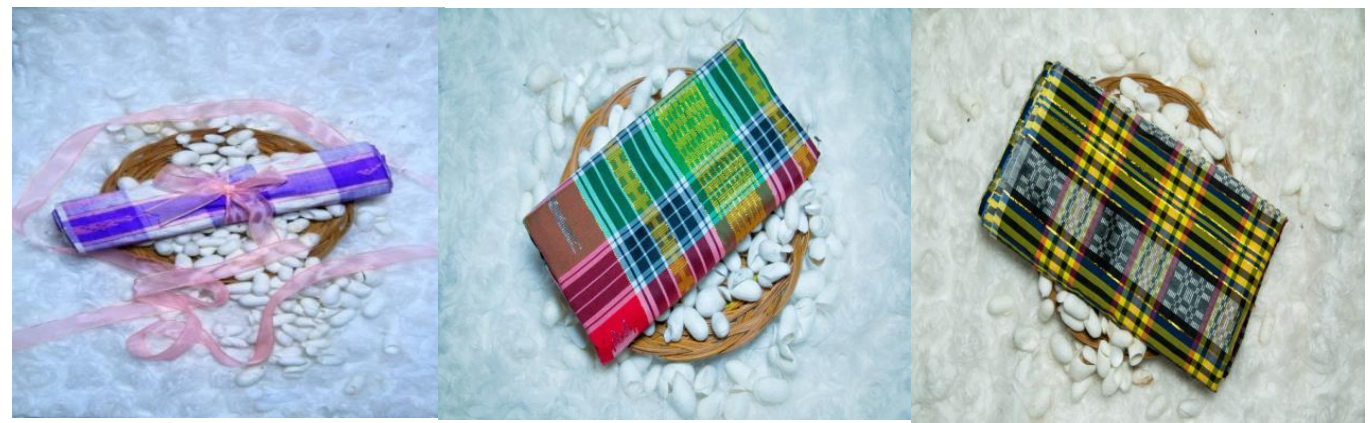

Gambar 4. Desain Foto Tenun pada Tampilan Website

Dengan di buatnya media promosi dengan media sosial dan brosur serta website tenun Cantikka yang tim lakukan dalam membantu pemasaran, memiliki dampak sekitar $10 \%$ terhadap peningkatan penjualan. Brosur yang disebarkan di wilayah Sulawesi Selatan (Makasar, Parepare dan kabupaten sekitar) memiliki dampak yang cukup signifikan terhadap promosi sehingga semakin banyak konsumen yang mengenal tenun cantika. Diharapkan kedepannya media promosi tersebut dapat memperluas pasar tenun cantika dan memperomosikan tenun tidak hanya di Sulawesi Selatan tetapi ke seluruh Indonesia bahkan ekspor.

\section{KESIMPULAN}

Berdasarkan dari pelaksanaan kegiatan yang telah dilakukan maka dihasilkan beberapa output seperti: Pembuatan website www.cantikasabbena.com,_Pembuatan Brosur, Pembuatan Kartu nama, Merancang desain foto tenun agar terlihat lebih menarik ketika ditampilkan di website, Pemasaran Tenun Cantikka mengalami sekitar 10\% peningkatan penjualan dan semakin banyak konsumen yang mengenal Tenun Cantikka.

\section{DAFTAR PUSTAKA}

Judy, S dan Raymond, F. (2013). EMarketing. Routlegde. 